\title{
A guide to echocardiographic assessment in children and adolescents with pulmonary hypertension
}

\author{
Astrid E. Lammers ${ }^{1}$, Christian Apitz ${ }^{2}$, Ina Michel-Behnke ${ }^{3}$, Martin Koestenberger ${ }^{4}$ \\ ${ }^{1}$ Pediatric Cardiology and Adult Congenital Heart Disease, University Hospital Münster, Münster, Germany; ${ }^{2}$ Pediatric Cardiology, University \\ Children's Hospital Ulm, Ulm, Germany; ${ }^{3}$ Division of Pediatric Cardiology, University Hospital for Children and Adolescents, Pediatric Heart \\ Centre Vienna, Medical University Vienna, Vienna, Austria; ${ }^{4}$ Division of Pediatric Cardiology and Pediatrics, Medical University Graz, Graz, Austria \\ Contributions: (I) Conception and design: AE Lammers, C Apitz; (II) Administrative support: All authors; (III) Provision of study materials or \\ patients: AE Lammers; (IV) Collection and assembly of data: AE Lammers, M Koestenberger; (V) Data analysis and interpretation: AE Lammers, M \\ Koestenberger; (VI) Manuscript writing: All authors; (VII) Final approval of manuscript: All authors. \\ Correspondence to: Dr. Astrid E. Lammers, MD. Pediatric Cardiology and Department for Adult Congenital and Structural Heart Disease, University \\ Hospital Münster, Albert-Schweitzer Campus 1, 48149 Münster, Münster, Germany. Email: Astrid.Lammers@ukmuenster.de.
}

\begin{abstract}
While the current definition of pulmonary hypertension $(\mathrm{PH})$ is still based on haemodynamic variables, transthoracic echocardiography is the most important diagnostic clinical tool for the first assessment and evaluation of a patient, in whom PH is suspected. In addition, it is the most important clinical modality in long term follow-up and the utility of echocardiography has widely been demonstrated in patients with PH. Echocardiography not only reveals the underlying cardiac morphology and diagnosis of any associated cardiac defects. In most patients with $\mathrm{PH}$ right ventricular (RV) pressure estimation is feasible. In addition, ventricular systolic and diastolic function, as well as ventricular-ventricular interactions of both ventricles can be assessed by using echocardiography. Maximizing the use of echocardiography by reporting several measures to gain information and quantitatively describe the parameters, that are linked to prognosis, seem particularly appealing in these children, in whom other advanced imaging modalities requiring anaesthesia is associated with a considerable risk. Herein we provide a practical approach and a concise and clinically applicable echocardiographic guidance and present basic variables, which should be obtained at any assessment. Moreover, we present additional advanced echocardiographic measures, that can be applied in a research or clinical setting when progressive $\mathrm{PH}$ needs a deeper insight to assess heart function, estimation of pulmonary artery pressures among others, by echocardiography. Finally, clinically relevant studies in view of the prognostic properties with a focus on the most important echocardiographic variables in pediatric $\mathrm{PH}$ are summarized.
\end{abstract}

Keywords: Pulmonary hypertension; echocardiography; children

Submitted Feb 26, 2021. Accepted for publication Jun 23, 2021.

doi: $10.21037 / \mathrm{cdt}-21-119$

View this article at: https://dx.doi.org/10.21037/cdt-21-119

\section{Introduction}

Transthoracic echocardiography is arguable the most important clinical tool for the first assessment and work-up in patients, when the suspicion of pulmonary hypertension $(\mathrm{PH})$ is being raised. While the current definition of $\mathrm{PH}$ is still based on haemodynamic variables and therefore demands a cardiac catheterization to confirm the diagnosis $(1,2)$.
Data from the TOPP registry suggested the potential combination of simple diagnostic non-invasive tests (chest $\mathrm{X}$-ray, electrocardiography and echocardiography) to rule out the presence of $\mathrm{PH}$. In fact, none of the 456 children with $\mathrm{PH}$ at the time of enrollment had all three tests considered normal (3).

Echocardiography not only reveals the underlying cardiac morphology and diagnosis of any associated 
Table 1 An overview of basic and additional + advanced echocardiographic variables and their role

\begin{tabular}{|c|c|}
\hline Parameter & Information gained \\
\hline Tricuspid regurgitation maximal velocity ${ }^{*}$ & $\begin{array}{l}\text { Estimation of right ventricular (RV) systolic pressure (RVSP)/systolic pulmonary artery } \\
\text { pressures (PAP) by adding right atrial pressure (RAP) }\end{array}$ \\
\hline Pulmonary regurgitation end-diastolic velocity* & Estimation of end-diastolic PAP by adding RAP \\
\hline RA dimensions/planimetry of the atria* & Assessment of atrial dimensions \\
\hline Pulmonary acceleration time (PAAT) $)^{*}$ & Severity of pulmonary hypertension $(\mathrm{PH})$ \\
\hline Tricuspid annular plane excursion (TAPSE)* & RV longitudinal function \\
\hline Left ventricular eccentricity index (LVEI)* & Flattening and bowing of interventricular septum as indirect marker of RVP \\
\hline Systolic-to-diastolic duration ratio & Time variables to assess systolic duration in proportion to diastolic duration \\
\hline RV base/apex ratio & Dilatation of the RV \\
\hline Tissue doppler assessment & RV and LV systolic and diastolic function ventricular-ventricular interactions (VVI) in $\mathrm{PH}$ \\
\hline Strain/strain rate measurement & $\begin{array}{l}\text { Assessment of global and regional ventricular function and ventricular-ventricular } \\
\text { interactions }(\mathrm{VVI}) \text { in } \mathrm{PH}\end{array}$ \\
\hline
\end{tabular}

Parameters with an * should be aimed to be assessed at any assessment.

cardiac defect, it also allows to estimate right ventricular (RV) pressures (directly or indirectly), which correspond to the peak systolic pulmonary artery pressure, in the absence of any RV outflow tract obstruction or pulmonary (artery) stenosis. In addition, echocardiography allows to assess ventricular systolic and diastolic function, as well as ventricular-ventricular interactions of both ventricles.

Moreover, echocardiography to date represents the most frequently used technique and most important diagnostic modality in the long-term follow-up of PH patients. Together with other clinical variables, it allows to assess $\mathrm{PH}$ severity, ventricular function as well as any disease progression during longitudinal follow-up in the regular medical service and assessment of patients with $\mathrm{PH}$.

Over the recent years, with a greater armamentarium of pharmacological treatment options, there is rising interest, which of the echocardiographic parameters might be surrogate parameters for prognosis in pediatric $\mathrm{PH}$.

Particularly since pediatric $\mathrm{PH}$ is rare and single center experience is often limited, uniform protocols for the echocardiographic assessment of children and adolescents with $\mathrm{PH}$ would be desirable. A uniform approach allows comparison of patient findings between different institutions or different investigators and facilitates multicenter research.

Herein we aim to introduce a comprehensive overview of echocardiographic parameters and an approach, that is practicable in clinical routine, that can be applied to any patient with $\mathrm{PH}$ ('Basic variables'). It is aimed to meet a balance of providing a thorough echocardiographic assessment, including the most important quantitative measures given the time constraints, most health professionals face in clinical practice. A focused but meaningful echocardiographic assessment is also desirable, particularly in younger children, in whom a long- echocardiographic study may not be tolerated (Table 1, measures *). Moreover, we present additional 'advanced echocardiographic measures', that can be applied in a research or clinical setting when progressive $\mathrm{PH}$ needs a deeper insight to assess heart function estimate pulmonary artery pressures among others, by echocardiography (Table 1).

Once the suspicion for $\mathrm{PH}$ is raised, at initial workup a complete comprehensive assessment with sequential analysis of the cardiac morphology is mandatory (4). 


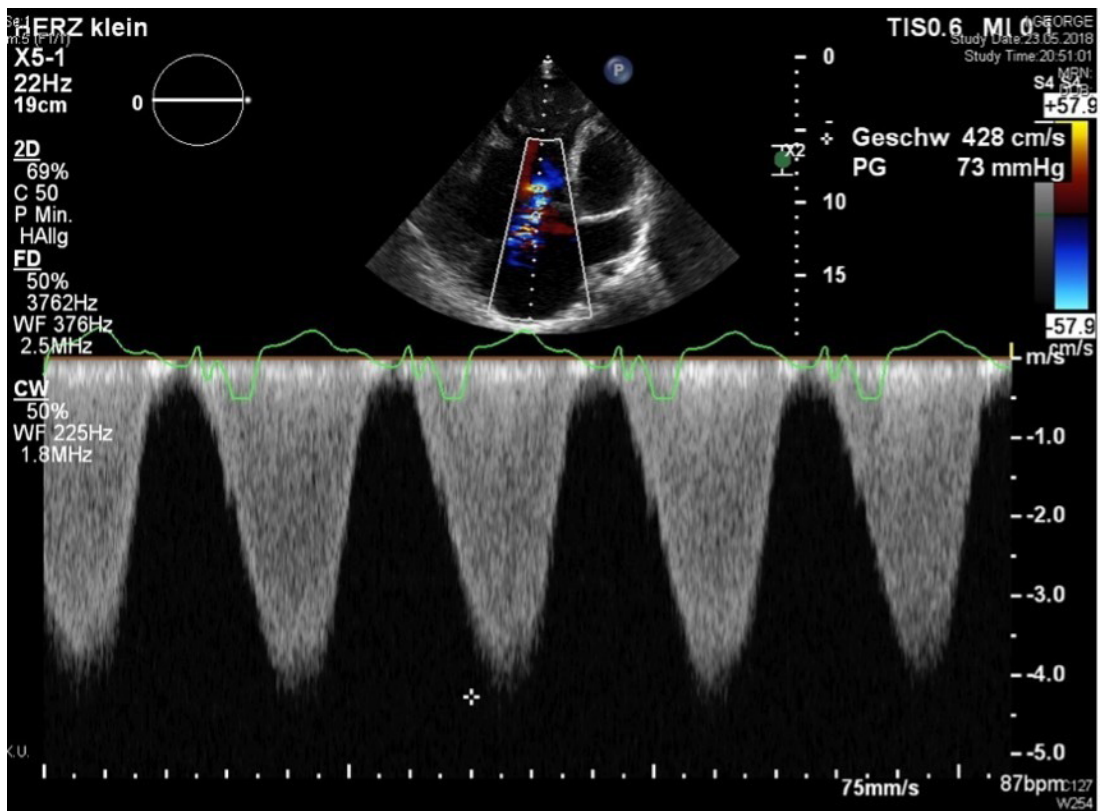

Figure $1 \mathrm{CW}$-Doppler interrogation of the tricuspid regurgitation signal from an apical 4-chamber view. Measurement of maximal velocity to estimate systolic right ventricular/pulmonary artery pressures by using the modified Bernoulli-equation and addition of right atrial pressure (in the absence of any right ventricular outflow tract obstruction or pulmonary stenosis).

Hemodynamically relevant or coincidental shunt lesions have to be ruled out, which may at least in part contribute to the development of PH. Infants within the first half year of life with a hemodynamically relevant shunt lesion are usually operated on without any previous cardiac catheterization. In older children or those with suspected established pulmonary vascular disease (PVD), assessment of mean pulmonary artery pressure (mPAP), left atrial pressure (LAP; or pulmonary capillary wedge pressure, PCWP), quantification of shunt volumes and calculation of pulmonary vascular resistance (PVR) via cardiac catherization is usually required to assess operability (5). In addition, testing with different agents with pulmonary vasodilatory properties can be performed during cardiac catheterization, to determine responsiveness of the pulmonary vasculature and assess disease severity, which is crucial for the decision-making process, and to guide therapy (6).

\section{Basic echocardiographic variables}

\section{Estimation of pulmonary artery pressures}

\section{Systolic pulmonary artery pressure}

In presence of a tricuspid valve regurgitation (TVR) signal with good quality (complete envelope of the Doppler tracing), systolic pulmonary artery pressures (PAP) can be assessed by using the modified Bernoulli equation utilizing the peak velocity of the regurgitation signal measured by CW- Doppler interrogation (Figure 1). In order to estimate the right ventricular systolic pressure (RVSP), a surrogate of systolic PAP (sPAP) in the absence of relevant pulmonary stenosis, corresponds to $4 \times$ the squared peak velocity of the TVR. The right atrial pressure (RAP)/ central venous pressure (CVP) has to be added.

$$
R V S P=4 \times[T V R \text { velocity }(\mathrm{m} / \mathrm{sec})]^{2}+R A P
$$

\section{Diastolic pulmonary artery pressure}

Another alternative indirect method to estimate the (end-) diastolic pulmonary artery pressure (dPAP) is to measure the end-diastolic velocity, assessed by Doppler, from a pulmonary regurgitation (PR) signal. Again, for the estimation of dPAP, RAP or CVP has to be added.

$$
d R A P=4 \times[P R \text { velocity }(\mathrm{m} / \mathrm{sec})]^{2}+R A P
$$

Pitfalls: in the presence of only trivial or very mild valvar regurgitation, a lack of a complete Doppler envelope usually leads to an underestimation of PAPs. Thus, in the absence 


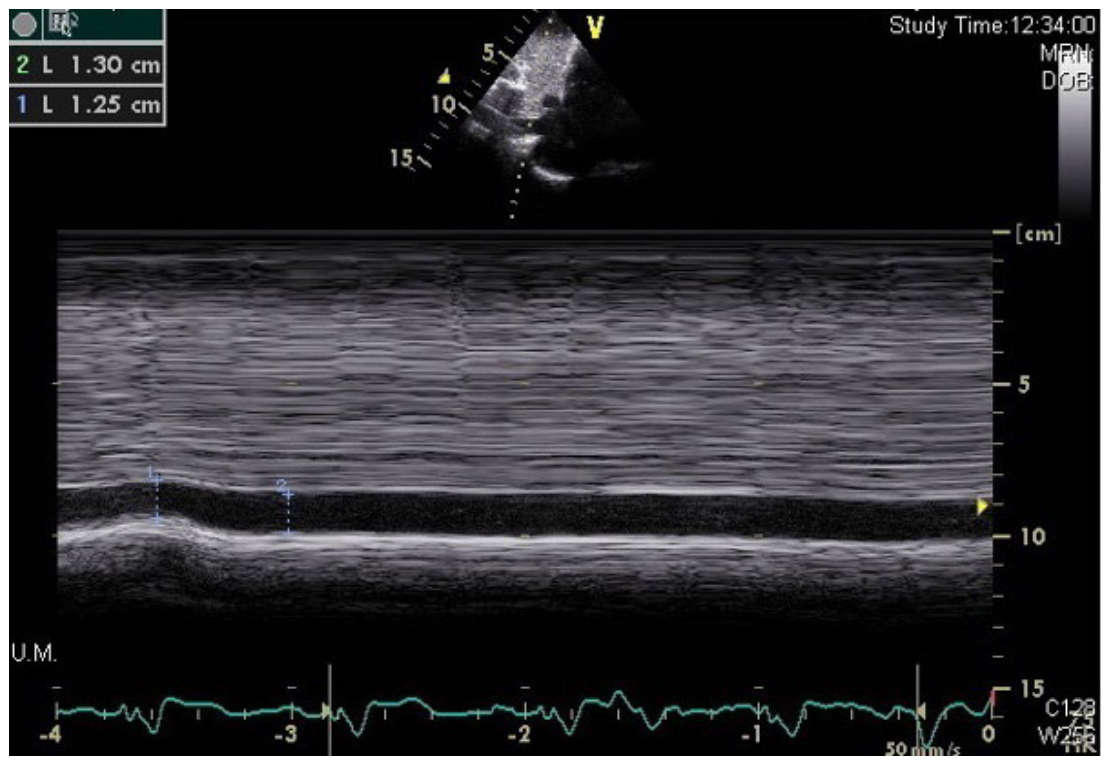

Figure 2 2D measurement of inferior caval vein (IVC) from a transabdominal view close to the IVC-right atrial insertion. Absolute dimension of IVC can be measured or reported as IVC collapsibility index = (maximal IVC diameter - minimal IVC diameter): max. IVC diameter $\times 100$.

of a sufficient TVR Doppler signal, reporting absolute numbers of PAP have to be undertaken with caution. As velocity determination is dependent on the angle of interrogation, it is useful to repeat these measurements from different echocardiographic views and angles for an accurate estimation.

In advanced $\mathrm{PH}$ and increased RAPs and severe TVR, the degree of pulmonary pressure elevation may be underestimated, assessed by the TVR signal only, as ventricular and atrial pressures may have adjusted and the pressure drop across the tricuspid valve may not accurately reflect the PAP any longer (7).

Of note, a lack of TVR or an insufficient signal (with an incomplete envelope) to estimate PAPs, does not imply that PAP is normal. Another critical pitfall is the interpretation of the estimated PAPs. In order to compare PAP measures, (change in) RV function has to be considered and taken into account for the interpretation of PAPs. Hence, a drop of estimated pressure does not necessarily suggest an improvement of $\mathrm{PH}$. In the setting of a chronic progressive disease, worsening impairment of right ventricular function has to be ruled out, as the evolvement of RVSP is the driving force for the TR velocity. That means, with increasingly compromised right ventricular systolic function, crude PAP estimations from TVR interrogation, do underestimate the degree of pulmonary vascular disease.

\section{Mean pulmonary artery pressure}

If mPAP is to be estimated by echocardiographic methods, the mean PAP can be gauged as follows: $\mathrm{mPAP}=0.61 \times$ systolic PAP $+2 \mathrm{mmHg}(8)$.

A TVR velocity of $>3.4 \mathrm{~m} / \mathrm{s}$, thus corresponds to a systolic PAP of approximately $50 \mathrm{mmHg}(+\mathrm{CVP})$ in accordance with presence of pulmonary hypertension (according to the former definition) $(7,9)$. As the formula for the calculation of the pulmonary pressures (see above) suggests, estimation of RAP/CVP is required.

\section{Estimation of right atrial pressure (RAP)/central venous pressure (CVP)}

Collapsibility of the inferior caval vein (IVC) with inspiration assessed by echocardiography allows an estimation of CVPs.

No significant correlation was found between IVC collapsibility index (IVCCI) and age, gender, or indexed RA volume. IVCCI is calculated as follows (Figure 2).

$I V C C I=(\max$ imal IVC diameter $-\min . I V C$ diameter $): \max . I V C$ diameter $\times 100$ 


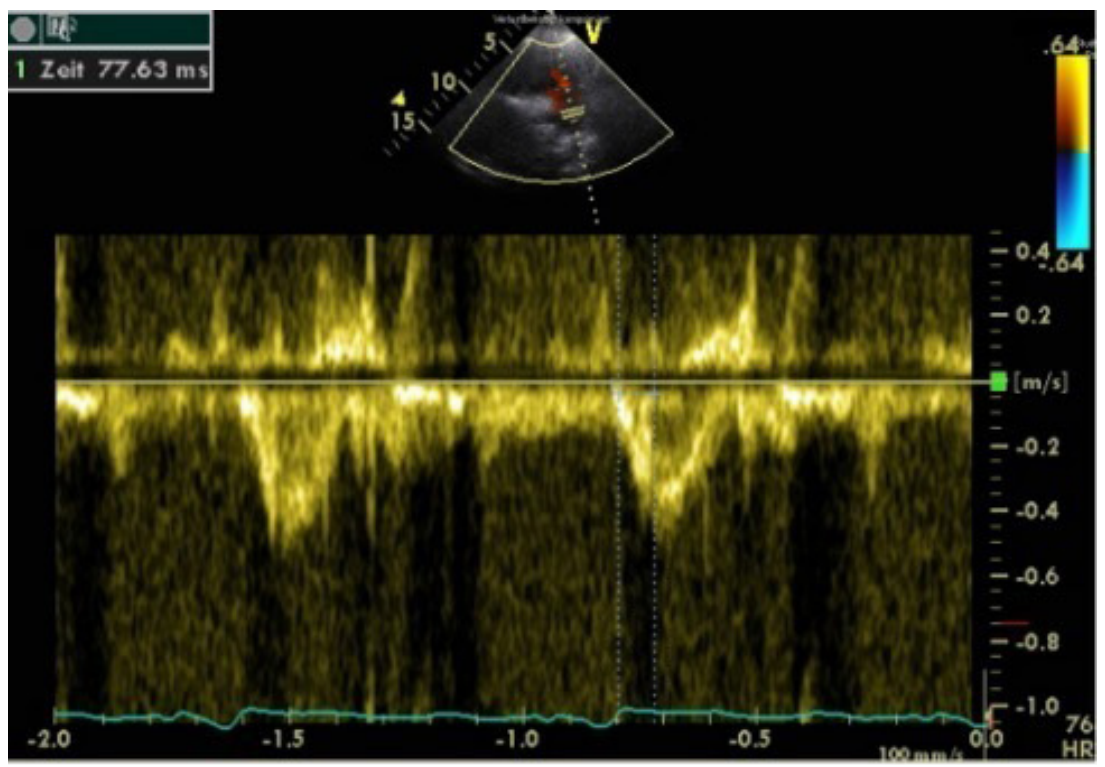

Figure 3 PW Doppler of antegrade flow into the pulmonary artery with measurement of the pulmonary acceleration time (PAAT). Interval from the onset of flow in the pulmonary artery to peak velocity of the flow signal (in ms).

Pediatric studies of healthy children have shown, that venous diameters increase predictably with growth, however IVCCI, compare closely with those reported in adults (10). Echocardiographic assessment of collapsibility index has shown a good correlation with CVP measurement in neonates and children (11).

There are some controversies with regards to the utility of IVCCI in children, where no clear correlation could be found. Arya et al. found that long axis IVC max provided an estimate of mean RAP (12).

According to the current ASE guidelines (13) an IVCCI of $50 \%$ discriminates between a normal respiro-phasic motility of the IVC (IVCCI $\geq 50 \%$ ). In adults, IVCCI values of $\geq 50 \%$ are thought to exclude the possibility of hemodynamic congestion when combined with maximum values of IVC diameter $\leq 21 \mathrm{~mm}$.

\section{Assessment of right atrial (RA) dimensions}

Atrial dimensions can be assessed by planimetry from an apical 4-chamber view. Worsening compliance and function of the right ventricle is transduced to the right atrium. While we often see atrial dilatation in children quite late in the course of the disease, it reflects a loss of venous pooling capacity and worsening of cardiac integrity. A pediatric study demonstrated that an active emptying fraction of $\geq 60 \%$ and a RV FAC $<25 \%$ correlated with clinical worsening (14). Progressive worsening of the RA reservoir and conduit function has been reported to describe RA deformation and performance, which have been shown to correlate with functional capacity, invasive hemodynamics and emerged as predictors for adverse outcome in children with $\mathrm{PH}$ (15).

\section{Pulmonary acceleration time (PAAT)}

For a long time, pulsed-wave Doppler interrogation of the PAAT has been an established surrogate marker for the PAP. It has been shown in adult cohorts that PAAT not only correlated with mPAP but also with the resistance PVR (9). There is an inverse linear relationship between PAP and PAAT.

PAAT is best determined from a parasternal short-axis view, placing the pulsed waved Doppler into the center of the proximal main pulmonary artery, assuring a good signal of pulmonary artery flow (16). PAAT is the interval measured from the onset of the flow in the pulmonary artery to peak velocity of the flow signal (in ms) as demonstrated in Figure 3.

One major advantage of PAAT is, that measurement is reported to be feasible in nearly all patients (99\%), even in the absence of a sufficient TVR envelope to estimate PAPs (16).

In healthy individuals, the PAAT should be $>110 \mathrm{~ms}$; a PAAT of $<100 \mathrm{~ms}$ is considered abnormal (17). As PAAT shortens when heart rate increases, the changes of hemodynamics during growth and maturation from infancy to adolescence and physiological decrease of heart 


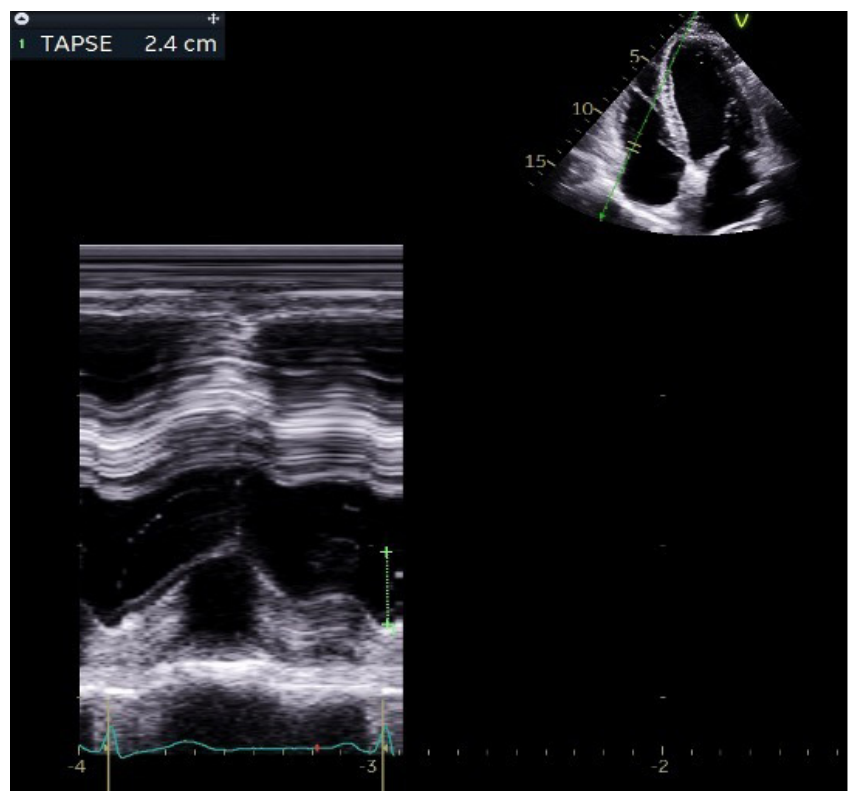

Figure 4 TAPSE measurement from an apical 4-chamber view, by placing the M-mode over the anterior right ventricular free wall at the level of the tricuspid valve insertion.

rate have to be encountered. Normal values for children have been established more recently by Koestenberger et al. in a large pediatric cohort of $>750$ children. In healthy children, PAAT increases in a non-linear fashion with age. PAAT positively correlated with age and body surface area, length and weight (9). As expected, a negative correlation was demonstrated with heart rate. Interestingly, females had shorter PAAT times than male individuals. This is well in keeping with other exercise studies of heart rate in normal children, in whom healthy girls have higher heart rate compared to boys of similar age $(18,19)$.

Koestenberger et al. demonstrated in a control group of 54 pediatric patients with $\mathrm{PH}$, that a decreased PAAT of a z-score $<2$ is predictive for the diagnosis (9). The usefulness of PAAT in children was confirmed in another pediatric study by Levy et al. (20).

Alternatively, to PAAT measurement, a pulsed waved Doppler interrogation can be obtained from the parasternal short axis view, by placing the Doppler sample in the RV outflow tract below the pulmonary artery valve. Like the shortened PAAT in individuals with $\mathrm{PH}, \mathrm{RV}$ ejection time (RVET) has also been shown to be decreased in $\mathrm{PH}$ patients. Expressing both values as ratio, PAAT/RVET is less dependent on variables like age, heart rate and body surface area (21). Therefore, it has also been found to be useful in children $(21,22)$.

Normal values for children for RVOT VTI are available and have been reported by Koestenberger $\mathrm{et} \mathrm{al}$. previously (23). RVOT VTI has been shown to correlate with PVRi and TRV with a good sensitivity and specificity particularly for higher values of pulmonary vascular resistances in both adults and children. Measurement of the RVOT VTI ratio provides a useful adjunct for patients, in whom TRV is only mild and sufficient Doppler interrogation is not feasible.

\section{Echocardiographic assessment of right ventricular function}

\section{Tricuspid annular plane excursion (TAPSE)}

Whilst other imaging techniques, like cardiac MRI allow accurate volumetric assessment of the RV, comprehensive echocardiographic quantitative assessment of the RV volume is much more difficult. Simple echocardiographic tools, based on simple geometrical shapes, cannot be applied to the RV due to its geometrical structure morphology and trabeculations.

Biplane interrogation using the modified Simpson technique is feasible, however a technically much more straight-forward tool has evolved as standard measure reflecting only one component of right ventricular contraction. The tricuspid annular plane excursion (TAPSE) represents the longitudinal systolic function of the RV (24). It describes the motion of the tricuspid annulus towards the apex. Although only a part of the complex contraction mechanics of the right ventricle is being reflected by this, it has been shown to correlate well with outcome and morbidity in PH (25). The TAPSE is measured using the M-mode from an apical four chamber view (Figure 4). TAPSE values increase from infancy to adolescence, agedependent normal values for TAPSE have been provided $(26,27)$. A decrease in TAPSE represents a surrogate for a general deterioration of global RV function, although other mechanical kinetic aspects of all other segments are not fully represented by this measurement. In particular, the radial component of RV contraction is not reflected by TAPSE, neither any segmental RV dysfunction. Although the process of RV contraction is much more complex, its clinical impact is relevant: for any decrease of $1 \mathrm{~mm}$ in TAPSE, the unadjusted risk of death increased by $17 \%$ (hazard ratio, 1.17) in an adult $\mathrm{PH}$ population (28). In addition, in serial echocardiographic assessments, TAPSE turned out as one of the predictive variables associated with outcome (25). 


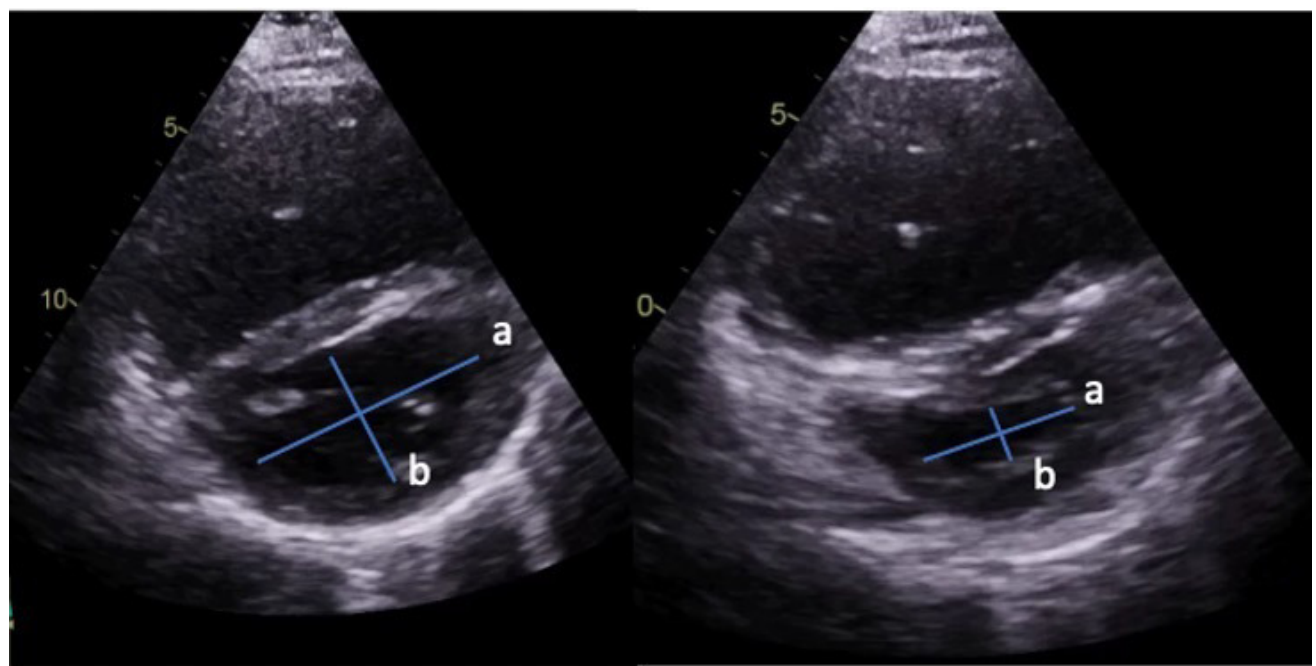

Figure 5 Left ventricular eccentricity index (LVEI) is measured from a parasternal short axis view of the ventricles, expressed as ratio of the minor axis of the LV parallel to the interventricular septum divided by the minor axis perpendicular to the septum.

\section{Left ventricular eccentricity index (LVEI)}

An elevated pulmonary artery and hence RV pressure leads to flattening of the interventricular septum (IVS). In the setting of severe PH and supra-systemic RV pressures, the IVS may even bow into the left ventricle. This leads to the typical 'D-shape' of the left ventricle in the parasternal short axis view. The abnormal septal motion also compromises left ventricular systolic and diastolic function (29-31). The quantification of septal shift represents the severity of RV pressure and is part of the ventricular-ventricular interaction.

However, the maximal leftward septal shift in $\mathrm{PH}$ often occurs at the time of early LV diastole (32). In accordance, a short mitral inflow time and a reversed mitral inflow $\mathrm{E} / \mathrm{A}$ ratio are frequently present in a pattern of delayed relaxation (30,32). Referring to this observation, a new TTE measure, entitled the post-systolic maximal eccentricity index (LVpsEIM), which is calculated at maximal septal flattening, was recently introduced for children $(33,34)$. VpsEIM measures were significantly increased in children with $\mathrm{PH}$ and correlated well with invasive hemodynamics and outcome measures (33).

Figure 5 illustrates the technique of measuring this unitless index. LVEI is measured from a parasternal short axis view of the ventricles, expressed as the ratio of the minor axis of the $\mathrm{LV}$ parallel to the interventricular septum divided by measuring the minor axis perpendicular to the septum (35). Amongst others, in adult patients with idiopathic pulmonary arterial hypertension (IPAH), an enddiastolic LVEI $>1.7$ has been shown to allow prognostic stratification of an adverse outcome (36).

However, the LVesEI as well as the LVpsEIM should be interpreted cautiously, especially in patients with $\mathrm{PH} / \mathrm{PAH}$ after surgical repair of CHD as the structure and shape of the IVS may be affected (e.g., due to ventricular patches) (37).

\section{Right ventricular fractional area change (RV FAC)}

The RV FAC is expressed as the ratio of the diastolic RV area-systolic RV area/diastolic RV area, measured from an apical 4-chamber view. This provides a reflection of the radial and longitudinal forces of the RV function (Figure 6).

In pediatric $\mathrm{PAH}$, an $\mathrm{RV} F A C<25 \%$ may indicate clinical worsening $(14,38,39)$.

The disadvantage of this measure is a considerably higher intra- and interobserver variability compared to TAPSE and the fact that it is less reproducible (28). In the setting of a dilated RV, a clear delineation of the curvature of the anterior wall may be obscured. A correlation between RV FAC, indexed RV stroke work and TAPSE has been shown in a pediatric cohort of patients with $\mathrm{PH}$ (40).

It has to be emphasized that all measures of the right ventricle are, to a certain degree dependent on central venous pressure and may vary with altering preload conditions. This applies for RV FAC, TAPSE and longitudinal strain. Further caution is warranted in interpreting the obtained values in ventilated patients. Changes of intrathoracic pressure and ventilatory mechanics cause changes particularly to the flow dynamics in the measures of the right heart. 


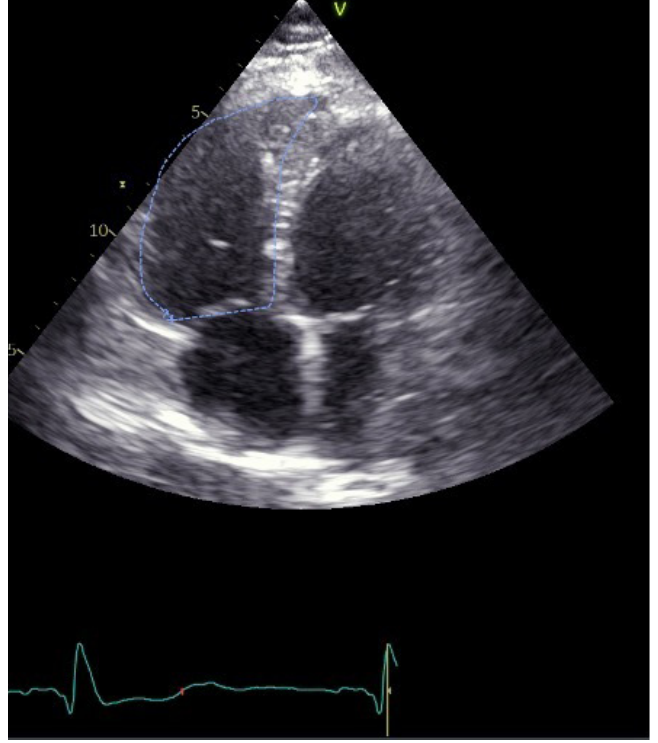

Figure 6 Right ventricular (RV) fractional area change (RV-FAC) is measured in an apical 4-chamber view by tracing the inner surface of the right ventricle in end-diastole and in systole. The FAC is reported as ratio of the (diastolic RV area - the systolic RV area)/diastolic RV area.

\section{Additional and advanced echocardiographic variables}

\section{Systolic-to-diastolic duration ratio}

In patients with an increased pulmonary vascular resistance, the duration of $\mathrm{RV}$ contraction is considerably prolonged at the expense of diastole (41). This sign of global RV function can be expressed by the systolic (S) to diastolic (D) duration ratio. It can be obtained by a Doppler flow measurement of the TR signal of $\mathrm{S}$ and $\mathrm{D}$ from an apical four-chamber view. The duration of the TR flow reflects $\mathrm{S}$, $\mathrm{D}$ duration is measured from the end of the TR flow signal to the new onset of TR in the next cardiac cycle (Figure 7). Thus, compared to healthy controls S/D ratio (usually $<1$ ) is prolonged in individuals with $\mathrm{PH}(42,43)$. An abnormal $\mathrm{S} / \mathrm{D}$ ratio can be a surrogate for $\mathrm{RV}$ dysfunction. This is even more pronounced at higher heart rates (41). Of note, the duration of $\mathrm{S}$ and $\mathrm{D}$ is heart rate dependent, and thus, worsened S/D duration ratios are especially seen in children with $\mathrm{PH}$ during tachycardia $(35,44)$. In children with $\mathrm{PH}$ an increased S/D ratio of $>1.4$ has been shown to correlate inversely with survival (44).

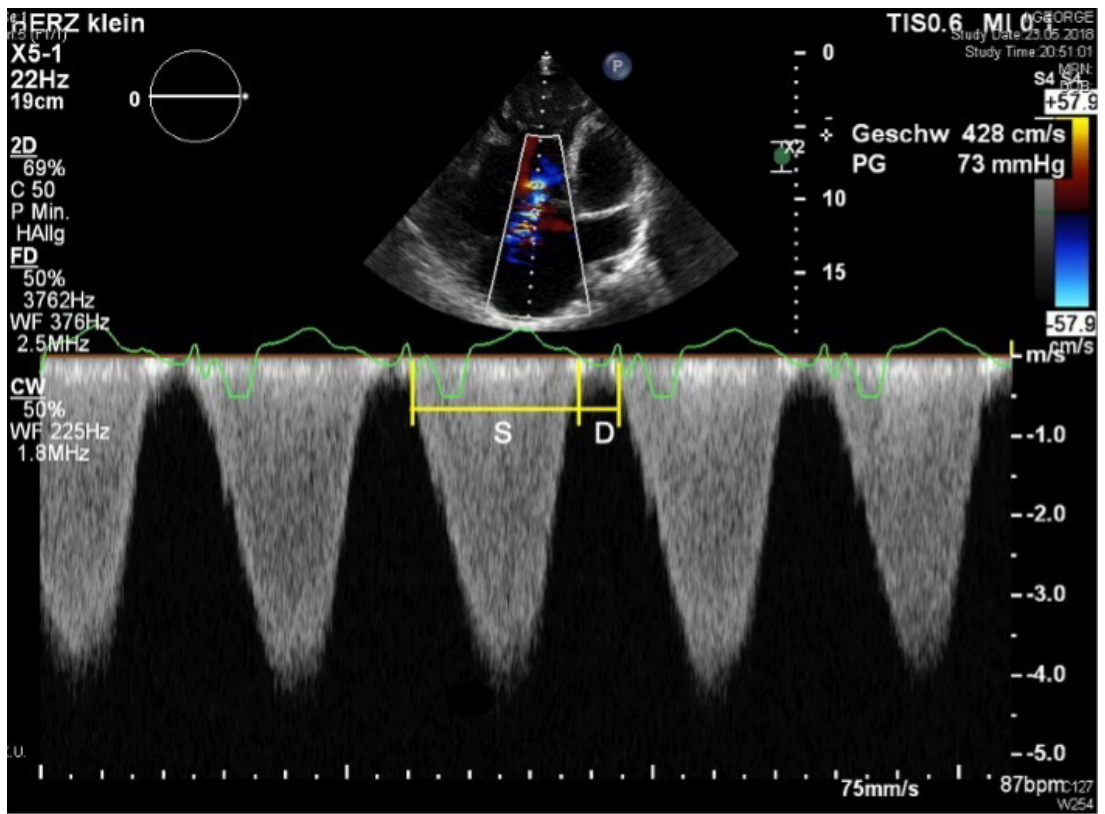

Figure 7 Systolic-diastolic duration ratio can be obtained from CW Doppler flow measurement of the tricuspid regurgitation (TR) signal of $\mathrm{S}$ and $\mathrm{D}$ from an apical 4-chamber view. The duration of the TR flow reflects S, while D is measured from the end of the TR flow signal to the new onset of TR in the next cardiac cycle. 


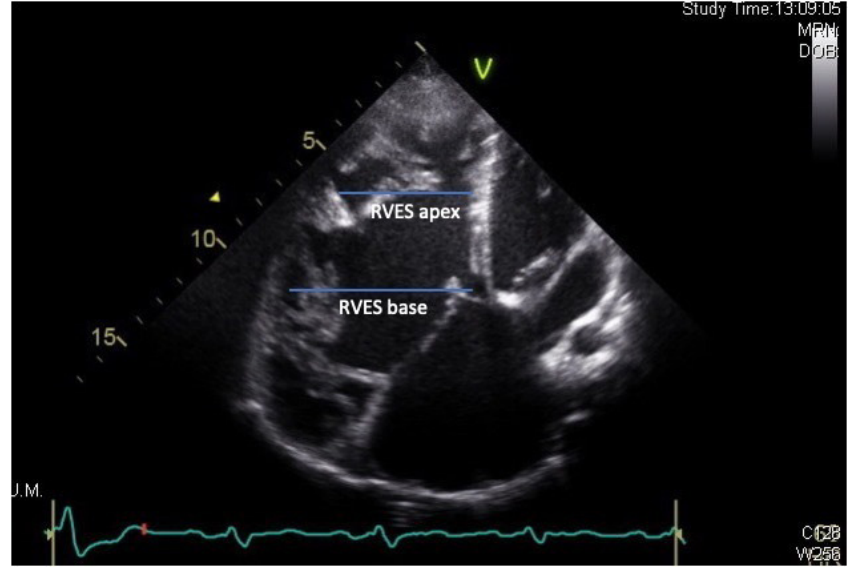

Figure $8 \mathrm{RV}$ base/apex ratio is measured is obtained at end-systole from an apical 4-chamber view. The RV internal diameter is measured at the base of the RV (RVES base), apical to the tricuspid valve anulus, whereas the apical internal diameter is taken at the level of the distal end of the moderator band (RVES apex).

\section{$R V$ baselapex ratio}

Another easy obtainable quantitative measure described to be useful in children with $\mathrm{PH}$ is the end-systolic RV base/ apex ratio $(45,46)$. This measure is obtained at end-systole from an apical 4-chamber view, where the RV internal diameter is measured at the base of the RV (RVES b), apical to the tricuspid valve anulus. The apical internal diameter is taken at the level of the distal end of the moderator band (RVES a) (Figure 8). Koestenberger et al. showed that in a cohort of 157 healthy children, the mean RVES b/a ratio were $1.87 \pm 0.22$. The normal values of the RVES b/a ratio slightly increased with increasing age $(\mathrm{r}=0.20, \mathrm{P}=0.011), \mathrm{BL}$ $(\mathrm{r}=0.17, \mathrm{P}=0.036)$, and showed a non-significant trend to an increase with $\mathrm{BSA}(\mathrm{r}=0.16, \mathrm{P}=0.05)$. The $\mathrm{RVES} \mathrm{b} / \mathrm{a}$ ratio was shown to decrease in children with $\mathrm{PAH}$ compared to age- and gender-matched healthy subjects (45). The RVES b/a ratio inversely correlated with both echocardiographic and hemodynamic indicators of increased RV pressure afterload, and with NYHA FC, suggesting the RVES b/a ratio to reflect disease severity in PAH children (45).

\section{Tissue Doppler assessment}

Tissue Doppler imaging (TDI) is a further tool, which allows to assess myocardial systolic and diastolic ventricular function by measuring myocardial velocities by $\mathrm{PW}$ Doppler. From an apical 4-chamber view PW-Doppler measures can be obtained from the lateral tricuspid valve annulus (Figure 9), the basal IVS and the LV lateral mitral annulus $(47,48)$.

The longitudinal systolic ventricular function is best expressed by the peak systolic (S') velocity. Whereas diastolic function is expressed by the early filling (E') and late $\left(A^{\prime}\right)$ diastolic velocities, where the latter expresses the contribution of atrial contraction to diastole. Abnormal values for TDI velocities have been described in children with $\mathrm{PH}$ and those with associated congenital heart disease, compared to normal controls $(31,47)$.

Absolute measures of TDI velocities vary with age and heart rate and normal values have been described for children (49). Thus, appropriate reference values for the different age groups must be applied to pediatric TDI studies.

In adults peak S' has been shown to correlate well to other echocardiographic parameters, e.g., RV FAC and TAPSE (50). In addition, peak S' has been shown to be inversely correlated with hemodynamic variables like mPAP and PVR (51). In adults with PH, a good correlation of tricuspid peak S' and RV EF obtained by cardiac MR imaging has been demonstrated (52). In addition, children with $\mathrm{PH}$ show an impairment of the peak tricuspid annular (S') velocity, with a decreasing of S' over the course time of longstanding elevation of the PAPs (47). Interestingly, in contrast to children with $\mathrm{PH}$, in children with right ventricular volume overload due to an atrial septal defect (amenable to interventional repair and no pulmonary vascular disease), tricuspid peak S' has been reported to be increased and normalizes after shunt closure $(53,54)$. A negative correlation of tricuspid diastolic TDI velocities with PAPs have also been reported in patients with atrial shunt lesions (55). The ratio of tricuspid E'/A' has been found to have the highest sensitivity and specificity, when used in conjunction with maximal tricuspid regurgitation velocity in distinguishing between patients with $\mathrm{PH}$ associated to congenital heart disease and healthy controls (55).

A low tricuspid E' has been described to be related to outcome in a pediatric cohort of children with idiopathic pulmonary hypertension (56).

$\mathrm{RV}$ dysfunction in advanced $\mathrm{PH}$, with shift of the interventricular septum, affects LV function. Ventricularventricular interactions are a well acknowledged phenomenon in $\mathrm{PH}$ physiology, as described above. Abnormal TDI measurements of the left lateral wall and interventricular septum may reveal these early changes 


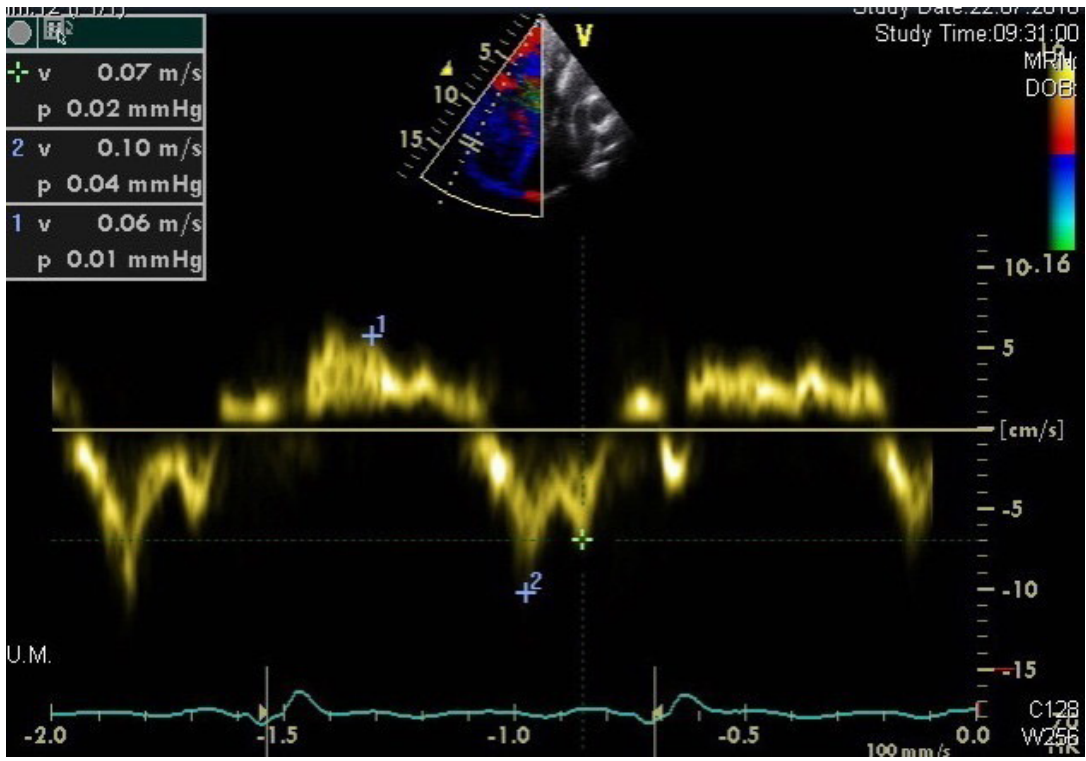

Figure 9 Tissue Doppler Imaging from an apical 4-chamber view with PW-Doppler placed on the right ventricular anterior wall at tricuspid valvar ring level.

of left ventricular compromise. The impact on the left ventricular hemodynamic integrity is shown by decreased measures of the TDI velocities of the left posterior wall.

TDI has also been found to be useful in patients with operated congenital heart disease, as TDI measures are independent of ventricular geometry and can even be used in patients with altered RV morphology or scaring of the RV from previous ventriculostomies, accordingly (57).

\section{$R V$ strain measurement}

A further tool to gain information on global as well as regional ventricular function are strain measurements. Myocardial deformation is described by strain, which is dimensionless. Strain rate provides information on myocardial deformation taking the time variable into account. Myocardial strain measures provide information on regional and global RV function $(58,59)$.

Normal values of cardiac deformation, strain and strain rate in children have been published (60-62). One advantage of this technique is, that it is less dependent on loading conditions as compared to the conventional parameters; this is especially true for $\mathrm{PH}$ associated to congenital heart disease (59).

In adult individuals with $\mathrm{PH}, \mathrm{RV}$ longitudinal peak systolic strain and strain rate have been demonstrated to be lower compared to healthy controls (63).

Children with IPAH show a decrease in RV longitudinal deformation parameters, as well as an impaired or absent transverse and post-systolic shortening, indicating RV dysfunction (64).

RV longitudinal free-wall strain correlates with clinical parameters, like functional class, 6-minute walk distance, (N-terminal pro)-B-type natriuretic peptide levels, and the presence of right heart failure (65). Additionally, it has proven to be a strong predictor of outcome as demonstrated in a large adult patient cohort $(65,66)$. For adult patients, a 1.46 higher risk of death has been reported per $6.7 \%$ decline in RV strain (66). While RV strain is defined as the mean value of the RV free wall in currently applied definitions (35), inclusion of the septal regions into the assessment have been shown to be useful $(32,67)$.

In a pediatric cohort of asymptomatic patients after Fallot repair, pulmonary regurgitation has been shown to be associated with impaired regional systolic RV function and impaired deformation indices, expressed by an abnormal strain and strain rate in various segments of the RV free wall and IVS (54). Regional strain and SR may be an early indicator of $\mathrm{RV}$ impairment before patients are symptomatic (54).

Serial assessment of RV systolic strain in adult $\mathrm{PH}$ patients on advanced therapies has shown, that an improvement of 
$>-5 \%$ of the absolute value in RV systolic strain at followup correlated with improvement of clinical status, favorable hemodynamics, and decrease in RV failure (68). In children with $\mathrm{PH}$, who started therapy with a prostacyclin analogon, a similar trend and an improvement in RV strain measures was observed. This suggests that RV strain may be an indicator of RV function in this population (69). RV strain and TAPSE were found to be worse in patients with $\mathrm{PH}$ who died compared to the survivors over a course of a five-year follow up duration period (70), whereas the RV strain appeared to be superior in the distinction between survivors and nonsurvivors $(71,72)$.

Significant correlations of 3D strain parameters with RV failure have also been reported in adults and in children with PH (70,73). Further research of the value of deformation indices particularly in the longitudinal follow-up of children with $\mathrm{PH}$ and its prognostic values is warranted and needs further clinical research.

\section{$R V$ diastolic function}

Diastolic dysfunction and increase in RAPs have been demonstrated to be associated with adverse outcome and mortality (74).

The assessment of RV echocardiographic measures is limited, as values vary with changing preload levels. Additionally, tricuspid inflow velocities are altered in the setting of severe tricuspid regurgitation.

For the evaluation of RV diastolic function, tricuspid inflow velocities (E, A, E/A), and tissue Doppler imaging at the lateral $\mathrm{RV}$ wall at the level of the tricuspid valvar annulus level TDI at (E', A', E'/A'), deceleration time and the isovolumic relaxation time (IVRT) can be measured by PW Doppler echocardiography from an apical fourchamber view.

The combination of tricuspid valvar inflow velocity and lateral peak RV velocity, expressed as ratio E/E' has been described to be useful assessing potential RV diastolic dysfunction (61). However, in children with cardiac shunt lesions, no correlation of end-diastolic pressure (RVEDP) and E/E' could be found. This is likely due to the preload dependency which may be variable in patients with left-toright shunting (72).

Reduced peak early diastolic velocities (E') have been reported in infants with $\mathrm{PH}$ (75) and in children with $\mathrm{PH}$ of different etiologies compared to normal controls (31). Invasive measurements of hemodynamic variables, like mPAP and RVEDP have been shown to inversely correlate with peak tricuspid valve E' velocity (75) in infants and also in children after surgical correction of their congenital heart disease (72).

As illustrated above, diastolic dysfunction directly translates into a pathological load of the right atrium. The function of the right atrium, measured with different modalities is compromised and shows impairment with worsening diastolic dysfunction of the RV $(14,76,77)$. While in children dilatation and compromise of the RA appear to occur quite late in the course of longstanding $\mathrm{PH}$ compared to adult patients with a similar degree of disease severity. Moreover, atrial rhythm disturbances, e.g., atrial flutter or fibrillation do occur more frequently in adults than in children, which further lead to impairment of right (and left) ventricular diastolic filling. In the setting of an elevated RVEDP, appropriate contraction of the atria with atrial systole is even more important for adequate ventricular filling in diastole. Adults with $\mathrm{PH}$ and an atrial flutter or fibrillation were shown to have an increased mortality if a sinus rhythm cannot be restored (78). In children and adolescents, atrial rhythm abnormalities occur much less frequently than in adults and aging patients. However, RA impairment is a serious clinical sign in children with $\mathrm{PH}$, that is associated with adverse outcome (76).

\section{The left ventricle and ventricular-ventricular interactions (VVI) in $\mathrm{PH}$}

A thorough morphological echocardiographic assessment of the left-sided structures of the heart is part of the anatomical sequential analysis and is of utmost importance for the diagnosis of $\mathrm{PH}$. Any morphological anomalies or obstructions of the left heart have to be ruled out, which may cause, or at least in part contribute to the elevation of mPAP, such as pulmonary venous, mitral or aortic stenosis.

Although we describe echocardiographic variables and measures for the right and left ventricle, right and left ventricular function cannot be regarded in isolation. The structure of the interventricular septum is shared by both ventricles. Thus, both ventricles are mechanically connected and physically coupled. Any hemodynamic changes, like an increase of RV pressure due to an elevated PVR in PH patients leads to a shift of the IVS towards the left ventricle. With mildly elevated pressures, a flattening of the IVS can be seen, particularly in end-systole. In patients with higher PAPs the IVS bows into the left ventricle, leading to the typical 'D-shape' of the $\mathrm{LV}$ in a parasternal short axis.

Left ventricular systolic function is often described by 
left ventricular ejection fraction (LV-EF) and fractional shortening (LV-FS).

While the M-mode measurement and use of the Teichholz formula is based on the assumption of an ellipsoid geometrical structure of the left ventricular cavity, this measurement can be flawed. Particularly in conditions where the geometrical structure of the left ventricle is altered, either due to morphological changes due associated congenital heart disease, previous surgery, abnormal wall motion (abnormal conduction) or in $\mathrm{PH}$ with significant septal shift towards the left ventricle, the geometrical shape of the left ventricular cavity is changed (31,79-81). For quantitative measure of left ventricular function, the modified Simpson formula can be used, as described elsewhere. In children, a decreased LVEF has been shown to be associated with an increased systolic PAP and PVRI (82).

Patients with $\mathrm{PH}$ often have a RV conduction delay or complete right bundle branch block. This leads to dyssynchrony and abnormal motion of the IVS.

Although not being obvious on conventional measures of left ventricular systolic function, such as LV-EF or LVFS, it has been shown, that TDI techniques, strain and strain rate may reveal early LV impairment. Peak systolic left ventricular wall velocities (S') have been shown to be reduced in children with $\mathrm{PH}(31,35,83)$.

Reduced septal longitudinal strain, strain and strain rate reduction at the lateral free LV wall (84), has been demonstrated in adults with $\mathrm{PH}$. The reduction of $\mathrm{LV}$ strain/strain rate has been reported to be most pronounced within the IVS (33).

In contrast, children with severe $\mathrm{PH}$, may show a reduction of septal LV strain, whereas the longitudinal strain of the LV free wall appears to be preserved (33). A direct association between $L V$ myocardial function, invasive hemodynamics, and RV myocardial function has been demonstrated (33).

In children, other echocardiographic variables, as outlined above, that demonstrate ventricular-ventricular interactions, e.g., LVEI and the RV/LV dimension ratio, have been shown to be associated with a worse FC, worse hemodynamics and higher NT-pro BNP levels (82).

\section{LV diastolic function}

In $\mathrm{PH}$ a leftward septal shift and prolonged RV systole can be noted, both of which are known to affect $\mathrm{LV}$ diastolic function (29). LV diastolic function is usually assessed by measuring the inflow pattern across the mitral valve into the left ventricle from an apical 4-chamber view. The first wave (E) represents the early filling component of the diastole of the left ventricle, followed by an -A wave, that is usually smaller in amplitude, which represents the second phase and the atrial contraction at the end of diastole (85). This inflow pattern is usually reported as a ratio E/A. In adults, a range of E/A ratio between 0.9 and 2 is thought to be normal. A reduced LV E/A ratio of $<0.9$ suggests an impaired relaxation of the $\mathrm{LV}$, while an increased $\mathrm{E} / \mathrm{A}$ ratio that exceeds 2 indicates a reduced $\mathrm{LV}$ compliance (86).

The combination of the early diastolic inflow velocity (E) and TDI derived measures at the lateral LV wall (E'), expressed as E/E' ratio has been shown to demonstrate $\mathrm{LV}$ diastolic dysfunction in adult patients. An E/E' ratio of $>14$ has been shown to indicate an increase in left atrial pressures (86).

However, identifying LV diastolic dysfunction is more challenging in children, as normal values underlie changes with heart rate and loading status. Given the changes of the left ventricular diastolic dynamics that are described with maturation, like an increase in left ventricular filling with growth, that is predominantly achieved by an increase of the early component of passive filling of the left ventricle; this ratio cannot be easily applied to children. Mitral E wave velocities increase during infancy (87-89), whereas atrial phase filling (A wave) velocities are found to be lower over time, with the decreasing heart rate in children. However, it has been found, that the atrial contribution to diastole remains relatively constant, as with reduction in A velocity, an increase in filling time is noted (87).

This stresses the importance to used age-related reference values for the judgement of an abnormal diastolic flow pattern in children $(88,89)$.

This explains, why in children, the E/E' ratio for the delineation of diastolic dysfunction has not been found to be useful. But even after using adjusted variables, E/E' ratio has been found to be within normal limits in the majority of children with underlying cardiomyopathy (90).

However, it has been shown, that children with $\mathrm{PH}$ present with $\mathrm{LV}$ diastolic dysfunction that is most consistent with an impaired relaxation and reduced myocardial deformation. In addition to the described physiological changes of LV inflow dynamics, there is considerable interindividual heterogeneity, that even the absolute values of $\mathrm{LV}$ measures of diastolic performance should be interpreted with caution $(88,91)$. The same applies to other potential useful echocardiographic variables, e.g., TDI Doppler measures, where published pediatric normative references 
should be used for the appropriate age groups (91).

Other echocardiographic parameters, that describe LV diastolic function, were found to be reduced (mitral E velocity and inflow duration, mitral E' and E'/A', septal E' and A', and LV basal global early diastolic circumferential strain rate), whereas mitral E deceleration time, LV isovolumic relaxation time (IVRT), mitral E/E', and pulmonary vein A wave duration were increased. These echocardiographic parameters correlated with invasively determined levels of PH severity (30). The impact and compromise of $\mathrm{LV}$ diastolic function is a result of ventricular-ventricular interactions $(30,34)$.

An indirect indicator of $\mathrm{LV}$ diastolic dysfunction is the quantitative measure of LA size/volume. In adults, LA dilatation is described to be in indicator for $\mathrm{LV}$ dysfunction (86). Normal values are available for children. In children with CHD, LA dilatation has been described to be associated with unfavorable hemodynamics and is prognostic for adverse outcome (92). LV diastolic dysfunction has also been linked to the septal deviation into the left ventricle with elevated RVPs/ PAPs and also prolongation of RV systole (29).

In patients with biventricular circulations, another ratio that has proven to be useful describing the quantitative relation of $\mathrm{RV}$ and $\mathrm{LV}$ dimensions. The $\mathrm{RV} / \mathrm{LV}$ ratio is a simple echocardiographic 2D measure, obtained from a PSAX view. Comparable to the LVEI it describes the degree of septal deviation and relation of the $\mathrm{RV}$ as compared to the LV. With worsening right ventricular dilatation, an increased $\mathrm{RV} / \mathrm{LV}$ ratio has been described in individuals with $\mathrm{PH}(15,82)$. Even this easy obtainable echocardiographic parameter has been shown to have prognostic properties (93).

\section{Presence of pericardial effusion (PE)}

New occurrence of a moderate or large pericardial effusion has been described to be a strong prognostic factor associated with adverse outcome and mortality in adult $\mathrm{PH}$ PAH patients (94). Although no solid data in children with $\mathrm{PH}$ exist to date, development of a PE is considered a bad clinical sign and is likely linked to adverse outcome.

\section{3-dimensional-(3D) echocardiography}

3D echocardiography could serve as a tool for a more distinct assessment of the RV, given its complex morphological tripartite structure.
Although it has been successfully used in the assessment of adults with $\mathrm{PH}$ for the determination of RV volumes and ejection fraction with a good accuracy and reproducibility as a study of 35 children with $\mathrm{PH}$ has shown, that measures from $3 \mathrm{D}$ echocardiography (RV-EF, end-systolic and diastolic volumes) correlated well with hemodynamic variables and natriuretic peptides (73).

The ratio of RV stroke volume to end-systolic volume (SV/ESV) has been shown to be an independent predictor of outcome in adults with $\mathrm{PH}$ and serves as volume estimate of RV-arterial coupling. SV/ESV has been shown to be decreased in children with $\mathrm{PH}$ and correlates with other echocardiographic variables, such as RV strain. In addition, $\mathrm{SV} / \mathrm{ESV}$ ratio is a strong predictor of adverse events in children with $\mathrm{PH}$ (73).

Although reference values of RV volumes and ejection fraction for different age groups in children exist $(95,96)$ and the potential use of measures obtained from $3 \mathrm{D}$ echocardiography has been demonstrated $(73,97)$. $3 \mathrm{D}$-echocardiography has not found entry in the routine clinical practice for the assessment of children with $\mathrm{PH}$ as yet.

\section{Summary}

By gross and large, echocardiography remains the hallmark for the initial assessment and in the longitudinal follow-up for patients with $\mathrm{PH}$ and is the imaging modality of choice.

For the initial assessment and diagnosis of $\mathrm{PH}$, further diagnostic imaging modalities, like CT and cardiac MRI are recommended to rule out other causes or driving factors for the PH. Particularly in older children, when no sedation or anesthesia is required, MRI can be a useful adjunct, providing additional information in patients with $\mathrm{PH}$.

Particularly nowadays, working with time constraints and high-volume patient turnover in outpatient clinics, which often do not meet the requirements for these complex patients, knowledge of the most important echocardiographic variables is valuable and assist to perform a focused but meaningful echocardiography.

By presenting these basic echocardiographic variables, we aimed to provide some guidance and meet a compromise, to keep the echocardiographic examination concise to the point but still gaining sufficient information for the clinician to appropriately judge the echocardiographic status, capture any potential changes or disease progression. Moreover, we introduce and discuss additional advanced echocardiographic variables, which can be useful for investigational research protocols or if a more thorough 
patients' follow- up is desired.

\section{Conclusions}

Although numerous echocardiographic variables are associated with adverse outcome and may predict prognosis in children with $\mathrm{PH}$, it is important to stress, that a patients' status should not be judged by a sole echocardiographic parameter alone. In patients in whom PAPs are not amenable for an accurate estimation, indirect signs for $\mathrm{PH}$ should be noted and documented. For the clinical judgement and decision-making process, it is important to look at the complete echocardiographic assessment, in addition to the clinical status and other functional clinical variables in a context.

\section{Acknowledgments}

Funding: None.

\section{Footnote}

Provenance and Peer Review: This article was commissioned by the editorial office, Cardiovascular Diagnosis and Therapy for the series "Pediatric Pulmonary Hypertension". The article has undergone external peer review.

Conflicts of Interest: The authors have completed the ICMJE uniform disclosure form (available at https://dx.doi. org/10.21037/cdt-21-119). The series "Pediatric Pulmonary Hypertension" was commissioned by the editorial office without any funding or sponsorship. Drs. AEL and CA served as the unpaid Guest Editors of the series. Dr. AEL reports consultancy work for Actelion Pharmaceuticals/ Johnson \& Johnson. The authors have no other conflicts of interest to declare.

Ethical Statement: The authors are accountable for all aspects of the work in ensuring that questions related to the accuracy or integrity of any part of the work are appropriately investigated and resolved.

Open Access Statement: This is an Open Access article distributed in accordance with the Creative Commons Attribution-NonCommercial-NoDerivs 4.0 International License (CC BY-NC-ND 4.0), which permits the noncommercial replication and distribution of the article with the strict proviso that no changes or edits are made and the original work is properly cited (including links to both the formal publication through the relevant DOI and the license). See: https://creativecommons.org/licenses/by-nc-nd/4.0/.

\section{References}

1. Rosenzweig EB, Abman SH, Adatia I, et al. Paediatric pulmonary arterial hypertension: updates on definition, classification, diagnostics and management. Eur Respir J 2019;53:1801916.

2. Simonneau G, Montani D, Celermajer DS, et al. Haemodynamic definitions and updated clinical classification of pulmonary hypertension. Eur Respir J 2019;53:1801913.

3. Beghetti M, Berger RM, Schulze-Neick I, et al. Diagnostic evaluation of paediatric pulmonary hypertension in current clinical practice. Eur Respir J 2013;42:689-700.

4. Anderson RH, Shirali G. Sequential segmental analysis. Ann Pediatr Cardiol 2009;2:24-35.

5. Kozlik-Feldmann R, Hansmann G, Bonnet D, et al. Pulmonary hypertension in children with congenital heart disease (PAH-CHD, PPHVD-CHD). Expert consensus statement on the diagnosis and treatment of paediatric pulmonary hypertension. The European Paediatric Pulmonary Vascular Disease Network, endorsed by ISHLT and DGPK. Heart 2016;102 Suppl 2:ii42-8.

6. Hansmann G, Apitz C. Treatment of children with pulmonary hypertension. Expert consensus statement on the diagnosis and treatment of paediatric pulmonary hypertension. The European Paediatric Pulmonary Vascular Disease Network, endorsed by ISHLT and DGPK. Heart 2016;102 Suppl 2:ii67-85.

7. Fisher MR, Forfia PR, Chamera E, et al. Accuracy of Doppler echocardiography in the hemodynamic assessment of pulmonary hypertension. Am J Respir Crit Care Med 2009;179:615-21.

8. Cerro MJ, Abman S, Diaz G, et al. A consensus approach to the classification of pediatric pulmonary hypertensive vascular disease: Report from the PVRI Pediatric Taskforce, Panama 2011. Pulm Circ 2011;1:286-98.

9. Koestenberger M, Grangl G, Avian A, et al. Normal Reference Values and z Scores of the Pulmonary Artery Acceleration Time in Children and Its Importance for the Assessment of Pulmonary Hypertension. Circ Cardiovasc Imaging 2017;10:e05336.

10. Kutty S, Li L, Hasan R, et al. Systemic venous diameters, collapsibility indices, and right atrial measurements in normal pediatric subjects. J Am Soc Echocardiogr 
2014;27:155-62.

11. Mugloo MM, Malik S, Akhtar R. Echocardiographic Inferior Vena Cava Measurement As An Alternative to Central Venous Pressure Measurement in Neonates. Indian J Pediatr 2017;84:751-6.

12. Arya B, Kerstein D, Leu CS, et al. Echocardiographic Assessment of Right Atrial Pressure in a Pediatric and Young Adult Population. Pediatr Cardiol 2016;37:558-67.

13. Rudski LG, Lai WW, Afilalo J, et al. Guidelines for the echocardiographic assessment of the right heart in adults: a report from the American Society of Echocardiography endorsed by the European Association of Echocardiography, a registered branch of the European Society of Cardiology, and the Canadian Society of Echocardiography. J Am Soc Echocardiogr 2010;23:685713; quiz 786-8.

14. Kumar S, Vadlamudi K, Kaddoura T, et al. Active right atrial emptying fraction predicts reduced survival and increased adverse events in childhood pulmonary arterial hypertension. Int J Cardiol 2018;271:306-11.

15. Jone PN, Schäfer M, Pan Z, et al. Right VentricularArterial Coupling Ratio Derived From 3-Dimensional Echocardiography Predicts Outcomes in Pediatric Pulmonary Hypertension. Circ Cardiovasc Imaging 2019;12:e008176.

16. Yared K, Noseworthy P, Weyman AE, et al. Pulmonary artery acceleration time provides an accurate estimate of systolic pulmonary arterial pressure during transthoracic echocardiography. J Am Soc Echocardiogr 2011;24:687-92.

17. Granstam SO, Björklund E, Wikström G, et al. Use of echocardiographic pulmonary acceleration time and estimated vascular resistance for the evaluation of possible pulmonary hypertension. Cardiovasc Ultrasound 2013;11:7.

18. Armstrong N, Welsman JR. Cardiovascular responses to submaximal treadmill running in 11 to 13 year olds. Acta Paediatr 2002;91:125-31.

19. Mahon AD, Anderson CS, Hipp MJ, et al. Heart rate recovery from submaximal exercise in boys and girls. Med Sci Sports Exerc 2003;35:2093-7.

20. Levy PT, Patel MD, Groh G, et al. Pulmonary Artery Acceleration Time Provides a Reliable Estimate of Invasive Pulmonary Hemodynamics in Children. J Am Soc Echocardiogr 2016;29:1056-65.

21. Habash S, Laser KT, Moosmann J, et al. Normal values of the pulmonary artery acceleration time (PAAT) and the right ventricular ejection time (RVET) in children and adolescents and the impact of the PAAT/RVET- index in the assessment of pulmonary hypertension. Int J Cardiovasc Imaging 2019;35:295-306.

22. Gaulton JS, Mercer-Rosa LM, Glatz AC, et al. Relationship between pulmonary artery acceleration time and pulmonary artery pressures in infants. Echocardiography 2019;36:1524-31.

23. Koestenberger M, Nage B, Ravekes W, et al. Right Ventricular Outflow Tract Velocity Time Integral Determination in 570 Healthy Children and in 52 Pediatric Atrial Septal Defect Patients. Pediatr Cardiol 2015;36:1129-34.

24. Miller D, Farah MG, Liner A, et al. The relation between quantitative right ventricular ejection fraction and indices of tricuspid annular motion and myocardial performance. J Am Soc Echocardiogr 2004;17:443-7.

25. Mazurek JA, Vaidya A, Mathai SC, et al. Followup tricuspid annular plane systolic excursion predicts survival in pulmonary arterial hypertension. Pulm Circ 2017;7:361-71.

26. Koestenberger $M$, Ravekes $W$, Everett $\mathrm{AD}$, et al. Right ventricular function in infants, children and adolescents: reference values of the tricuspid annular plane systolic excursion (TAPSE) in 640 healthy patients and calculation of z score values. J Am Soc Echocardiogr 2009;22:715-9.

27. Kurath-Koller S, Avian A, Cantinotti M, et al. Normal Pediatric Values of the Subcostal Tricuspid Annular Plane Systolic Excursion (S-TAPSE) and Its Value in Pediatric Pulmonary Hypertension. Can J Cardiol 2019;35:899-906.

28. Forfia PR, Fisher MR, Mathai SC, et al. Tricuspid annular displacement predicts survival in pulmonary hypertension. Am J Respir Crit Care Med 2006;174:1034-41.

29. Burkett DA, Slorach C, Patel SS, et al. Left Ventricular Myocardial Function in Children With Pulmonary Hypertension: Relation to Right Ventricular Performance and Hemodynamics. Circ Cardiovasc Imaging 2015;8:e003260.

30. Burkett DA, Slorach C, Patel SS, et al. Impact of Pulmonary Hemodynamics and Ventricular Interdependence on Left Ventricular Diastolic Function in Children With Pulmonary Hypertension. Circ Cardiovasc Imaging 2016;9:e004612.

31. Lammers AE, Haworth SG, Riley G, et al. Value of tissue Doppler echocardiography in children with pulmonary hypertension. J Am Soc Echocardiogr 2012;25:504-10.

32. Friedberg MK. Imaging Right-Left Ventricular Interactions. JACC Cardiovasc Imaging 2018;11:755-71.

33. Burkett DA, Patel SS, Mertens L, et al. Relationship Between Left Ventricular Geometry and Invasive 
Hemodynamics in Pediatric Pulmonary Hypertension. Circ Cardiovasc Imaging 2020;13:e009825.

34. Hansmann G. Left Ventricular Diastolic Dysfunction in Pediatric Pulmonary Hypertension. Circ Cardiovasc Imaging 2016;9:e005527.

35. Koestenberger M, Friedberg MK, Nestaas E, et al. Transthoracic echocardiography in the evaluation of pediatric pulmonary hypertension and ventricular dysfunction. Pulm Circ 2016;6:15-29.

36. Ghio S, Klersy C, Magrini G, et al. Prognostic relevance of the echocardiographic assessment of right ventricular function in patients with idiopathic pulmonary arterial hypertension. Int J Cardiol 2010;140:272-8.

37. Koestenberger M, Hansmann G. Left Ventricular Geometry and Near-Simultaneous Invasive Hemodynamics in Pediatric Pulmonary Hypertension. Circ Cardiovasc Imaging 2020;13:e010787.

38. Bernardo RJ, Haddad F, Couture EJ, et al. Mechanics of right ventricular dysfunction in pulmonary arterial hypertension and heart failure with preserved ejection fraction. Cardiovasc Diagn Ther 2020;10:1580-603.

39. Sato T, Tsujino I, Oyama-Manabe N, et al. Right atrial volume and phasic function in pulmonary hypertension. Int J Cardiol 2013;168:420-6.

40. Di Maria MV, Younoszai AK, Mertens L, et al. RV stroke work in children with pulmonary arterial hypertension: estimation based on invasive haemodynamic assessment and correlation with outcomes. Heart 2014;100:1342-7.

41. Sarnari R, Kamal RY, Friedberg MK, et al. Doppler assessment of the ratio of the systolic to diastolic duration in normal children: relation to heart rate, age and body surface area. J Am Soc Echocardiogr 2009;22:928-32.

42. Friedberg MK, Silverman NH. The systolic to diastolic duration ratio in children with hypoplastic left heart syndrome: a novel Doppler index of right ventricular function. J Am Soc Echocardiogr 2007;20:749-55.

43. McCabe C, Vranesic II, Verdes MC, et al. Right ventricular systolic to diastolic duration ratio: A novel predictor of outcome in adult idiopathic pulmonary arterial hypertension. Int J Cardiol 2019;293:218-22.

44. Alkon J, Humpl T, Manlhiot C, et al. Usefulness of the right ventricular systolic to diastolic duration ratio to predict functional capacity and survival in children with pulmonary arterial hypertension. Am J Cardiol 2010;106:430-6.

45. Koestenberger M, Avian A, Gamillscheg A, et al. Right ventricular base/apex ratio in the assessment of pediatric pulmonary arterial hypertension: Results from the
European Pediatric Pulmonary Vascular Disease Network. Clin Cardiol 2018;41:1144-9.

46. Raza F, Dillane C, Mirza A, et al. Differences in right ventricular morphology, not function, indicate the nature of increased afterload in pulmonary hypertensive subjects with normal left ventricular function. Echocardiography 2017;34:1584-92.

47. Koestenberger $M$, Nagel B, Ravekes W, et al. Tricuspid annular peak systolic velocity ( $\left.\mathrm{S}^{\prime}\right)$ in children and young adults with pulmonary artery hypertension secondary to congenital heart diseases, and in those with repaired tetralogy of Fallot: echocardiography and MRI data. J Am Soc Echocardiogr 2012;25:1041-9.

48. Van de Veire NR, De Sutter J, Bax JJ, et al. Technological advances in tissue Doppler imaging echocardiography. Heart 2008;94:1065-74.

49. Eidem BW, McMahon CJ, Cohen RR, et al. Impact of cardiac growth on Doppler tissue imaging velocities: a study in healthy children. J Am Soc Echocardiogr 2004;17:212-21.

50. Saxena N, Rajagopalan N, Edelman K, et al. Tricuspid annular systolic velocity: a useful measurement in determining right ventricular systolic function regardless of pulmonary artery pressures. Echocardiography 2006;23:750-5.

51. Gurudevan SV, Malouf PJ, Kahn AM, et al. Noninvasive assessment of pulmonary vascular resistance using Doppler tissue imaging of the tricuspid annulus. J Am Soc Echocardiogr 2007;20:1167-71.

52. Wahl A, Praz F, Schwerzmann M, et al. Assessment of right ventricular systolic function: comparison between cardiac magnetic resonance derived ejection fraction and pulsed-wave tissue Doppler imaging of the tricuspid annulus. Int J Cardiol 2011;151:58-62.

53. Eyskens B, Brown SC, Claus P, et al. The influence of pulmonary regurgitation on regional right ventricular function in children after surgical repair of tetralogy of Fallot. Eur J Echocardiogr 2010;11:341-5.

54. Eyskens B, Ganame J, Claus P, et al. Ultrasonic strain rate and strain imaging of the right ventricle in children before and after percutaneous closure of an atrial septal defect. J Am Soc Echocardiogr 2006;19:994-1000.

55. Cevik A, Kula S, Olgunturk R, et al. Doppler tissue imaging provides an estimate of pulmonary arterial pressure in children with pulmonary hypertension due to congenital intracardiac shunts. Congenit Heart Dis 2013;8:527-34.

56. Takatsuki S, Nakayama T, Jone PN, et al. Tissue Doppler 
imaging predicts adverse outcome in children with idiopathic pulmonary arterial hypertension. J Pediatr 2012;161:1126-31.

57. Pauliks L. Tissue doppler myocardial velocity imaging in infants and children--a window into developmental changes of myocardial mechanics. Echocardiography 2013;30:439-46.

58. Weidemann F, Jamal F, Kowalski M, et al. Can strain rate and strain quantify changes in regional systolic function during dobutamine infusion, B-blockade, and atrial pacing-implications for quantitative stress echocardiography. J Am Soc Echocardiogr 2002;15:416-24.

59. Weidemann F, Jamal F, Sutherland GR, et al. Myocardial function defined by strain rate and strain during alterations in inotropic states and heart rate. Am J Physiol Heart Circ Physiol 2002;283:H792-9.

60. Levy PT, El-Khuffash A, Patel MD, et al. Maturational Patterns of Systolic Ventricular Deformation Mechanics by Two-Dimensional Speckle-Tracking Echocardiography in Preterm Infants over the First Year of Age. J Am Soc Echocardiogr 2017;30:685-698.e1.

61. Levy PT, Sanchez Mejia AA, Machefsky A, et al. Normal ranges of right ventricular systolic and diastolic strain measures in children: a systematic review and metaanalysis. J Am Soc Echocardiogr 2014;27:549-60, e3.

62. Morris DA, Krisper M, Nakatani S, et al. Normal range and usefulness of right ventricular systolic strain to detect subtle right ventricular systolic abnormalities in patients with heart failure: a multicentre study. Eur Heart J Cardiovasc Imaging 2017;18:212-23.

63. Li Y, Xie M, Wang X, et al. Right ventricular regional and global systolic function is diminished in patients with pulmonary arterial hypertension: a 2-dimensional ultrasound speckle tracking echocardiography study. Int J Cardiovasc Imaging 2013;29:545-51.

64. Driessen MMP, Meijboom FJ, Hui W, et al. Regional right ventricular remodeling and function in children with idiopathic pulmonary arterial hypertension vs those with pulmonary valve stenosis: Insights into mechanics of right ventricular dysfunction. Echocardiography 2017;34:888-97.

65. Fine NM, Chen L, Bastiansen PM, et al. Outcome prediction by quantitative right ventricular function assessment in 575 subjects evaluated for pulmonary hypertension. Circ Cardiovasc Imaging 2013;6:711-21.

66. Jone PN, Hinzman J, Wagner BD, et al. Right ventricular to left ventricular diameter ratio at endsystole in evaluating outcomes in children with pulmonary hypertension. J Am Soc Echocardiogr 2014;27:172-8.
67. Friedberg MK, Redington AN. Right versus left ventricular failure: differences, similarities, and interactions. Circulation 2014;129:1033-44.

68. Hardegree EL, Sachdev A, Villarraga HR, et al. Role of serial quantitative assessment of right ventricular function by strain in pulmonary arterial hypertension. Am J Cardiol 2013;111:143-8.

69. Hopper RK, Wang Y, DeMatteo V, et al. Right ventricular function mirrors clinical improvement with use of prostacyclin analogues in pediatric pulmonary hypertension. Pulm Circ 2018;8:2045894018759247.

70. Vitarelli A, Mangieri E, Terzano C, et al. Threedimensional echocardiography and 2D-3D speckletracking imaging in chronic pulmonary hypertension: diagnostic accuracy in detecting hemodynamic signs of right ventricular (RV) failure. J Am Heart Assoc 2015;4:e001584.

71. Okumura K, Humpl T, Dragulescu A, et al. Longitudinal assessment of right ventricular myocardial strain in relation to transplant-free survival in children with idiopathic pulmonary hypertension. J Am Soc Echocardiogr 2014;27:1344-51.

72. Okumura K, Slorach C, Mroczek D, et al. Right ventricular diastolic performance in children with pulmonary arterial hypertension associated with congenital heart disease: correlation of echocardiographic parameters with invasive reference standards by high-fidelity micromanometer catheter. Circ Cardiovasc Imaging 2014;7:491-501.

73. Jone PN, Schäfer M, Pan Z, et al. 3D echocardiographic evaluation of right ventricular function and strain: a prognostic study in paediatric pulmonary hypertension. Eur Heart J Cardiovasc Imaging 2018;19:1026-33.

74. Kassem E, Humpl T, Friedberg MK. Prognostic significance of 2-dimensional, M-mode, and Doppler echo indices of right ventricular function in children with pulmonary arterial hypertension. Am Heart J 2013;165:1024-31.

75. Patel N, Mills JF, Cheung MM. Assessment of right ventricular function using tissue Doppler imaging in infants with pulmonary hypertension. Neonatology 2009;96:193-9; discussion 200-2.

76. Jone PN, Schäfer M, Li L, et al. Right Atrial Deformation in Predicting Outcomes in Pediatric Pulmonary Hypertension. Circ Cardiovasc Imaging 2017;10:e006250.

77. Querejeta Roca G, Campbell P, Claggett B, et al. Right Atrial Function in Pulmonary Arterial Hypertension. Circ Cardiovasc Imaging 2015;8:e003521; discussion e003521.

78. Olsson KM, Nickel NP, Tongers J, et al. Atrial flutter and 
fibrillation in patients with pulmonary hypertension. Int J Cardiol 2013;167:2300-5.

79. Meinel K, Koestenberger M, Sallmon H, et al. Echocardiography for the Assessment of Pulmonary Hypertension and Congenital Heart Disease in the Young. Diagnostics (Basel) 2020;11:49.

80. Puwanant S, Park M, Popović ZB, et al. Ventricular geometry, strain, and rotational mechanics in pulmonary hypertension. Circulation 2010;121:259-66.

81. Truong U, Meinel K, Haddad F, et al. Update on noninvasive imaging of right ventricle dysfunction in pulmonary hypertension. Cardiovasc Diagn Ther 2020;10:1604-24.

82. Koestenberger M, Sallmon H, Avian A, et al. Ventricularventricular interaction variables correlate with surrogate variables of clinical outcome in children with pulmonary hypertension. Pulm Circ 2019;9:2045894019854074.

83. van Loon RL, Roofthooft MT, Hillege HL, et al. Pediatric pulmonary hypertension in the Netherlands: epidemiology and characterization during the period 1991 to 2005 . Circulation 2011;124:1755-64.

84. Toro R, Cabeza-Letrán ML, Quezada M, et al. Impaired right and left ventricular mechanics in adults with pulmonary hypertension and congenital shunts. J Cardiovasc Med (Hagerstown) 2016;17:209-16.

85. Schirmer H, Lunde P, Rasmussen K. Mitral flow derived Doppler indices of left ventricular diastolic function in a general population; the Tromso study. Eur Heart J 2000;21:1376-86.

86. Nagueh SF, Smiseth OA, Appleton CP, et al. Recommendations for the Evaluation of Left Ventricular Diastolic Function by Echocardiography: An Update from the American Society of Echocardiography and the European Association of Cardiovascular Imaging. J Am Soc Echocardiogr 2016;29:277-314.

87. Bu'Lock FA, Mott MG, Martin RP. Left ventricular diastolic function in children measured by Doppler echocardiography: normal values and relation with growth. Br Heart J 1995;73:334-9.

88. Cantinotti M, Giordano R, Scalese M, et al. Nomograms for mitral inflow Doppler and tissue Doppler velocities in Caucasian children. J Cardiol 2016;68:288-99.

89. Schmitz L, Koch H, Bein G, et al. Left ventricular diastolic function in infants, children, and adolescents. Reference values and analysis of morphologic and physiologic determinants of echocardiographic Doppler flow signals during growth and maturation. J Am Coll Cardiol 1998;32:1441-8.

90. Dragulescu A, Mertens L, Friedberg MK. Interpretation of left ventricular diastolic dysfunction in children with cardiomyopathy by echocardiography: problems and limitations. Circ Cardiovasc Imaging 2013;6:254-61.

91. Mori K, Hayabuchi Y, Kuroda Y, et al. Left ventricular wall motion velocities in healthy children measured by pulsed wave Doppler tissue echocardiography: normal values and relation to age and heart rate. J Am Soc Echocardiogr 2000;13:1002-11.

92. Taggart NW, Cetta F, O'Leary PW, et al. Left atrial volume in children without heart disease and in those with ventricular septal defect or patent ductus arteriosus or hypertrophic cardiomyopathy. Am J Cardiol 2010;106:1500-4.

93. Zeng WJ, Sun YJ, Xiong CM, et al. Prognostic value of echocardiographic right/left ventricular enddiastolic diameter ratio in idiopathic pulmonary arterial hypertension. Chin Med J (Engl) 2011;124:1672-7.

94. Shimony A, Fox BD, Langleben D, et al. Incidence and significance of pericardial effusion in patients with pulmonary arterial hypertension. Can J Cardiol 2013;29:678-82.

95. Laser KT, Karabiyik A, Körperich H, et al. Validation and Reference Values for Three-Dimensional Echocardiographic Right Ventricular Volumetry in Children: A Multicenter Study. J Am Soc Echocardiogr 2018;31:1050-63.

96. Maffessanti F, Muraru D, Esposito R, et al. Age-, body size-, and sex-specific reference values for right ventricular volumes and ejection fraction by three-dimensional echocardiography: a multicenter echocardiographic study in 507 healthy volunteers. Circ Cardiovasc Imaging 2013;6:700-10.

97. Jone PN, Patel SS, Cassidy C, et al. Three-dimensional Echocardiography of Right Ventricular Function Correlates with Severity of Pediatric Pulmonary Hypertension. Congenit Heart Dis 2016;11:562-9.

Cite this article as: Lammers AE, Apitz C, Michel-Behnke I, Koestenberger M. A guide to echocardiographic assessment in children and adolescents with pulmonary hypertension. Cardiovasc Diagn Ther 2021;11(4):1160-1177. doi: 10.21037/ cdt-21-119 